\title{
Cataract surgery and methods of wound closure: a review
}

\author{
This article was published in the following Dove Press journal: \\ Clinical Ophthalmology \\ 22 May 2015 \\ Number of times this article has been viewed
}

\section{Cynthia Matossian' \\ Sarah Makari² \\ Richard Potvin ${ }^{2}$ \\ 'Matossian Eye Associates, Pennington, $\mathrm{NJ},{ }^{2}$ Science in Vision, Akron, NY, USA}

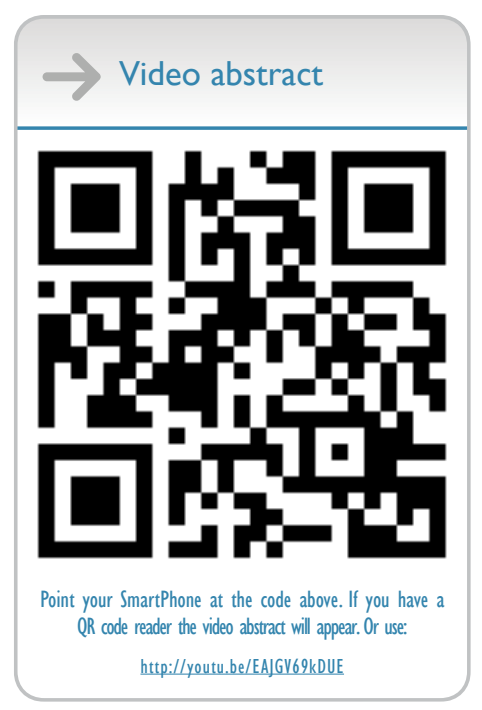

Correspondence: Richard Potvin Science in Vision, 6197 Dye Road, Akron, NY I 400 I, USA

$\mathrm{Tel}+\mathrm{I} 4076976008$

Fax +I 7164425110

Email rick@scienceinvision.com

\begin{abstract}
Clear corneal incisions are routinely used in cataract surgery, but watertight wound closure may not always be achieved, which can increase the risk for anterior chamber fluid egress or ocular surface fluid ingress. A new US Food and Drug Administration-approved ocular sealant appears to have good efficacy in sealing clear corneal incisions; its use may be indicated when wound integrity is in question.
\end{abstract}

Keywords: clear corneal incisions, wound closure, sealant, suture, stromal hydration, cataract surgery

\section{Introduction}

Sutureless clear corneal incisions (CCIs) have become the standard of care when performing routine cataract surgery due to multiple advantages; these advantages include the decreased induction of corneal astigmatism from a suture, reduced cost of surgery without a suture, and the relative ease of creating a presumed watertight corneal incision. ${ }^{1}$ However, there is a concern that leaving incisions without definitive closure may increase the risk for wound leaks.

Current evidence suggests that anterior chamber content egress is not uncommon. ${ }^{2-4}$ One study found that in 100 cases, almost one-third of the incisions leaked. ${ }^{2}$ Another case report demonstrated fluid egress in a seemingly watertight $1.4 \mathrm{~mm} \mathrm{CCI}{ }^{3}$ There is also a documented case of iris prolapse through the CCI, 2 weeks after cataract surgery, due to postoperative (PO) vomiting. ${ }^{4}$

During the early PO period, intraocular pressure (IOP) fluctuation may be common since patients may inadvertently rub their eye, dab instilled eye medications from their eye, or squeeze their eyelids; lid squeezing has been demonstrated to produce IOP spikes up to $110 \mathrm{mmHg} .{ }^{5-7}$ Even if nominal or no pressure is applied to the eye, wound leaks may still occur. ${ }^{8}$ In a recent multicenter study comprising 487 patients receiving single-plane incisions, fluid egress was observed in $97.6 \%$ of patients when $\leq 1.0$ ounce force $(0.278$ Newtons) was applied and in $48.8 \%$ of patients prior to pressure application. ${ }^{8}$ The concern is that a wound that is not watertight may potentially signify a pathway for pathogen entry into the anterior chamber with each blink or eyelid squeeze. ${ }^{9}$ A leaking CCI on the first PO day was associated with a 44-fold increased risk of endophthalmitis. ${ }^{10}$

Of particular concern is the potential for hypotony, which can create a relative vacuum and possibly result in poor wound stability ${ }^{1,7}$ with an increased risk of infection or toric intraocular lens (IOL) rotation. ${ }^{11}$ Eyes with an IOP less than $5 \mathrm{mmHg}$ are especially susceptible to wound gapes. ${ }^{7}$ Even an IOP less than $10 \mathrm{mmHg}$ (observed in $11 \%$ or $7 / 64$ patients in one study) ${ }^{12}$ could cause wound separation. ${ }^{7}$ Hypotony can be present during the first 24 PO hours in the presence of a seemingly watertight sutureless incision. ${ }^{13}$ 
Certain situations may further weaken the CCI and make it more prone to leaking. ${ }^{12}$ These include complicated cataract surgeries with prolonged surgical time or increased manipulation through the incision noted in the presence of mature cataracts, zonular dehiscence, or zonular laxity. ${ }^{12,14}$ In addition, phacotrabeculectomy, ${ }^{15}$ vitrectomy, ${ }^{16}$ and laserassisted in situ keratomileusis (LASIK) ${ }^{17}$ may cause wound compromise. LASIK, especially hyperopic LASIK because of the associated peripheral thinning, can weaken the cornea and compromise wound healing. ${ }^{17}$ Case reports in the literature document ocular complications during routine vitrectomy, including retinal detachment, resulting from a fluid leak through the cataract wound created 0-14 days prior to the vitreoretinal surgery. ${ }^{16}$ Definitive wound closure is important in these cases. It is also important to achieve a watertight seal in patients with diabetes or immunocompromised individuals, who can be at an increased risk of infection. Patients who are monocular or are methicillin-resistant Staphylococcus aureus positive may also benefit from a watertight incision.

\section{Identifying the leak: Seidel testing}

Seidel testing is the most common method used to test for leaks. During this test, fluorescein is applied to the incision and the surgeon looks for fluid egress. ${ }^{18}$ The reliability of Seidel testing has been in question because there have been several reported instances where Seidel testing was negative (suggesting no leak) in the presence of wound gaping. ${ }^{5,18}$

During a modified Seidel test, the surgeon often uses a Weck-Cel sponge to apply an unknown amount of force to the edge of the incision while looking for a leak. ${ }^{18}$ One of the problems with this technique is the lack of standardization of the amount of force applied to determine the presence of a leak. ${ }^{19}$ One study developed an ocular force gauge to apply a known amount of pressure to the wound. ${ }^{19}$ The results from this study showed that one ounce force was sufficient to cause approximately $90 \%$ (20/22) of the main corneal biplane incisions and side port incisions to leak. ${ }^{19}$ At the conclusion of surgery, it appears that applying one ounce force using this ocular force gauge may be more useful in determining fluid egress than the subjective application of the Weck-Cel sponge.

\section{Methods to minimize wound leaks Block anesthesia}

Topical anesthetics are short-lived and allow patients to blink or squeeze their eyes; block anesthesia that lasts up to 4 hours has been suggested to reduce leaks. ${ }^{20}$ The effectiveness of block anesthesia is unlikely to last long enough to prevent potential complications related to wound instability because the integrity of incisions could still be compromised up to 1 week postoperatively. ${ }^{21}$ Moreover, there are additional increased risks associated with block anesthesia including increased cost and increased patient discomfort. ${ }^{22}$

\section{Intracameral antibiotics}

In two large studies, one in Sweden and the other in Portugal, intracameral antibiotics were suggested to be one of the main reasons for the low rates of negative sequelae that may be associated with wound compromise. ${ }^{23,24}$ However, routine use of intracameral antibiotics in the US has not been adopted. There are no ready-to-use US Food and Drug Administration (FDA)-approved intracameral antibiotics. There may be risks, such as toxic anterior segment syndrome (TASS), associated with the reconstitution of antibiotic solutions originally indicated for external use. ${ }^{25}$

\section{Corneal incision architecture}

Incision architecture is known to have an effect on wound leakage. Several studies have reported that stepped threeplane square incisions can minimize leaks. ${ }^{26-28}$ However, creating a perfectly square three-plane incision in every case is difficult; one study showed that even when a surgeon aims to create a three-plane incision, the incision will actually be a three-plane incision in a small percentage of eyes $(32 \%$ in the study in question). ${ }^{1}$ In addition, even a properly created triplanar beveled wound may not be strong enough to resist leakage if subjected to external pressures or IOP fluctuations. ${ }^{29}$

The size of the incision may also have an effect on fluid egress. ${ }^{14,21}$ While intuitively a smaller incision size would seem to allow less area for pathogen accumulation, incisions too small may need to be enlarged; this may render them more unstable than larger incisions that were not subject to stretching. ${ }^{14,21}$ Even untouched side port incisions, which are typically very small, did not demonstrate a watertight seal after IOP fluctuation. ${ }^{5}$ Therefore, smaller incisions may not necessarily be better at resisting leaks. ${ }^{14,21}$

Recently, femtosecond laser-assisted cataract surgery has gained attention in the literature. One study found that the manual and laser incisions had equivalent ability to close wounds. ${ }^{30}$ A case report demonstrated that laser-created CCI may leak. ${ }^{31}$ Another study found that the laser-created incision was accurately constructed which led to improved wound closure and better predictability of the surgically induced astigmatism. ${ }^{32}$ Of note is that the majority of these studies were completed on uncomplicated cases. ${ }^{32}$ While more research is needed in this area, current evidence does not support the use of femtosecond lasers as a definitive way to ensure wound closure. 


\section{Equipment and techniques}

Surgical equipment and techniques play a very important role in reducing the potential for wound leaks. For instance, the material of the blade used to create the corneal incision may affect the structural soundness of the wound and possibly the visual outcome. Diamond blades are generally considered to be sharper and provide more predictable incision configuration than metal blades; one study found that after a 1-month follow-up, the two blade types resulted in different corneal thicknesses but wound healing and surgically induced astigmatism and aberrations were similar between the two groups. ${ }^{33}$ Surgeon preference may be a factor in choosing a blade type. In addition, surgeon preference as well as the density of the cataract will likely influence the choice of phacoemulsification needle. An aim to reduce phacoemulsification time and ultrasound energy during cataract surgery is likely to decrease the risk of thermal injury to the wound site and better preserve its integrity; this is especially important to consider with smaller incisions which may be more susceptible to damage from the ultrasound energy. To curtail mechanical damage to the wound site, manual manipulation of the incision needs to be minimized. The phacoemulsification technique may also have an impact on improving wound integrity. ${ }^{34}$ One study found that microcoaxial phacoemulsification may be advantageous over biaxial phacoemulsification by providing a more optimal healing arcuate incision configuration; $;{ }^{34}$ smaller incision angles are considered more favorable in decreasing the chance of wound gapes. ${ }^{33}$

\section{Wound closure: current standards of care \\ Stromal hydration}

Stromal hydration is one of the most frequently used methods to seal sutureless corneal incisions. ${ }^{35}$ The literature is divided over the effectiveness of stromal hydration. One study of 80 patients found that stromal hydration was effective. ${ }^{36}$ Another study reported a $66.7 \%$ leak rate with stromally hydrated incisions. ${ }^{19}$ It has been suggested that leaks may occur as the effect of stromal hydration wears off. ${ }^{37}$ To this point, it is unclear how long the effects of stromal hydration last; various studies suggest anywhere from 1 day ${ }^{38}$ to 1 week. ${ }^{39}$ The duration of stromal hydration may vary due to its presumed dependence on the endothelial pumping mechanism for a particular eye. ${ }^{37} \mathrm{~A}$ new hydration technique focusing on hydrating the stromal pocket as opposed to the roof and walls of the incision was associated with significantly less leaking, but this newer technique may carry an additional risk of epithelial damage and/or increased astigmatism. ${ }^{40}$ Further research appears warranted in this area.
There are some potential negative effects from stromal hydration. Hydrating the incision was reported in one study to increase corneal staining, corneal edema, and anterior chamber reaction, and to decrease visual acuity. ${ }^{37}$ There is a risk of an increase in IOP, especially if a patient already has endothelial cell dysfunction. ${ }^{37,41}$ Localized Descemet's membrane detachment is sometimes associated with stromal hydration, ${ }^{41}$ although some surgeons argue for other factors contributing to this complication..$^{42}$ One study points out that stromal hydration may have little, if any, added value since hydrating the incision occurs inherently during surgery. ${ }^{1}$

\section{Sutures}

Sutures are routinely used when a leak is observed at the completion of surgery. It is not clear whether sutured incisions allow a better or similar seal when compared with stromal hydration..$^{14,43}$ Sutured incisions have been reported to leak in $23.8 \%(5 / 21)$ of cases when less than/or equal to one ounce force was applied to the wound; ${ }^{19}$ with provocation, as high as $34 \%$ of sutures have been noted to leak. ${ }^{8}$ Even without provocation, one study suggested that approximately $67 \%(6 / 9)$ of human globes receiving a single radial suture to seal a two-plane incision may have a disrupted or weakened wound site. ${ }^{44}$ In addition, loose or broken sutures are more susceptible to leaks and infections, whereas tight sutures may distort the wound, increase astigmatism, and reduce visual acuity..$^{14,25,45-49}$

The application of sutures is time consuming, and associated with various complications including subconjunctival hemorrhage, eye irritation, and foreign body sensation. ${ }^{8,14,50}$ On histological examination, sutures were associated with substantial tissue injury and vacuole development. ${ }^{51}$ While the suture is designed to seal the wound, sutures can change wound architecture to the point where they provide an increased risk of infection. ${ }^{44,52}$

Several studies have recognized the increased risk of suture-related complications and strongly advocate for early removal of nonabsorbable sutures as soon as epithelialization has occurred. ${ }^{47,49,50}$ In one study, $12.6 \%$ (23/183) of eyes required earlier and unscheduled suture removal due to infection, foreign body sensation, conjunctival injection, astigmatism, or an elevated, loose, or broken suture. ${ }^{8}$ Bringing the patient back for suture removal has been seen by some as inconvenient for the patient, time consuming for the surgeon, and costly, while increasing the risk for infection. ${ }^{46,50,53}$ One study reported that in $66.7 \%(2 / 3)$ of cases, there was a resultant corneal infection after removing a broken suture..$^{48}$ 


\section{Wound closure products}

It is evident that current standard of care for wound closure techniques are inadequate; there is a need for better and more definitive wound closure. A means of closure that is nontoxic, noninflammatory, and nondisruptive to surrounding tissue would be ideal if it did not induce astigmatism, create opacities, or cause neovascularization. ${ }^{9,54,55}$ It would need to be prepared and applied easily, quickly, and efficiently with the ability to secure a watertight seal until re-epithelialization occurs. ${ }^{9,14,54,55}$ The ideal product would have to be biocompatible, biodegradable, and transparent while still providing easy visualization during application. ${ }^{14,55}$ The following section outlines some wound closure products.

\section{Cyanoacrylate}

Cyanoacrylate is similar to "super glue" 56 and it has been used alone or as a component of another adhesive in sealing wounds in ophthalmology. ${ }^{43,56}$

\section{Advantages}

One of the main advantages of cyanoacrylate is that it is an extremely strong adhesive with the ability to seal incisions and withstand the highest IOP. ${ }^{57,58}$ In addition, cyanoacrylate has demonstrated good bacteriostatic activity. ${ }^{56,59}$

\section{Disadvantages}

Despite cyanoacrylate having a bacteriostatic effect, infections were still visualized underneath the adhesive. ${ }^{56}$ In addition, cyanoacrylate has been shown to be toxic, ${ }^{56}$ opaque, ${ }^{56}$ inflexible, ${ }^{56}$ inflammatory, ${ }^{43,56,58}$ and cannot be reabsorbed. ${ }^{56}$ Cyanoacrylate has been associated with necrosis, fibrosis, foreign body sensation, irritation, discomfort, and hyperemia with debris visibly present inside the wound. ${ }^{57,58}$ Also, it may not allow sufficient time for repositioning. ${ }^{43}$

\section{Fibrin}

Fibrin is another sealant that has been studied and used in ophthalmology.

\section{Advantages}

Fibrin is considered flexible, nontoxic, noninflammatory, biodegradable over weeks, and promotes wound healing through collagen cross-linking. ${ }^{56-60}$ Fibrin can prevent egress of fluid but probably only with modest pressure..$^{51,61}$

\section{Disadvantages}

Fibrin has been shown to be a relatively weaker adhesive when compared to cyanoacrylate. ${ }^{58,59}$ It is also not bacteriostatic but may be utilized to transport antibiotics. ${ }^{59}$ Fibrin is expensive and requires preparation. ${ }^{56,58,62}$ There is also an increased potential risk of viral and prion disease transmission. ${ }^{56,62}$

\section{Corneal welding}

Corneal welding has been studied in sealing clear corneal cataract incisions.

Some of the noted advantages of corneal welding is that it takes $25-45$ seconds to weld and provides good astigmatism control without substantial inflammation. ${ }^{63,64} \mathrm{~A}$ disadvantage of corneal welding is that it requires very careful application of light-absorbing dyes because they are dangerous and toxic if allowed to enter the anterior chamber. ${ }^{51,64}$ In addition, welding is known to denature collagen fibers through heat. ${ }^{60}$ This can result in tissue shrinkage of the cornea which may distort the cornea and reduce visual acuity. ${ }^{60}$ Histology studies show that collagen fibers were not parallel in eyes receiving corneal welding. ${ }^{64}$ Solders, which use similar principles, are often not flexible. ${ }^{50}$

\section{Polyethylene glycol-based products}

Polyethylene glycol (PEG)-based compounds have gained attention in the recent literature because they have many of the requirements for an ideal wound closure product. They are biocompatible and have been frequently used in artificial tears and contact lenses. ${ }^{8,56}$ As with any new product, the main downside is cost, but with time this is likely to be less of an issue. ${ }^{56}$

OcuSeal ${ }^{\circledR}$ liquid adhesive ocular bandage (Beaver-Visitec International, Ltd., Oxfordshire, UK; Becton, Dickinson and Company, Franklin Lakes, NJ, USA) was tested in human cadaver eyes and corneal incisions showed no sign of egress at the highest IOP $(246 \mathrm{mmHg}){ }^{65}$ OcuSeal was applied to CCIs in human subjects and was compared with incisions that only received stromal hydration and to incisions that only received sutures. ${ }^{14}$ The results showed that the ocular bandage was safe and provided more definitive wound closure when compared to stromal hydration and resulted in less astigmatism and less foreign body sensation when compared to sutures. ${ }^{14}$ The preparation and application of the liquid adhesive was fast (less than 30 seconds) and it was found to be quick and easy to use. ${ }^{14}$ OcuSeal is currently CE (European Conformity) marked but not FDA-approved.

The main disadvantage to using OcuSeal was that it cured too fast to allow sufficient time for proper application. ${ }^{14}$ More studies are warranted using this adhesive to determine clinical applicability.

To date, the ReSure ${ }^{\circledR}$ Sealant (Ocular Therapeutix, Inc., Bedford, MA, USA) is the most studied PEG sealant, with the 
largest trials performed on human subjects in the PEG-based sealant group. The ReSure Sealant is a PEG hydrogel polymer made up of PEG, trilysine, buffering salts, and water. ${ }^{8}$ A blue color is present to improve visualization during application but dissipates in hours, leaving a transparent hydrogel over the incision. ${ }^{8}$ The ReSure Sealant is a single-use product that is mixed and applied within several seconds, and polymerizes in less than 30 seconds. ${ }^{8}$ The sealant was considered easy to apply $99.7 \%$ of the time. ${ }^{66,67}$ The ReSure Sealant is currently FDA-approved for the management of CCI wound leaks and the prevention of fluid egress after cataract surgery. ${ }^{68}$

In the early PO period, the ReSure Sealant was reported to maintain IOP anywhere from 11 to $29 \mathrm{mmHg}$, higher than a control group where IOP was 5-23 mmHg. ${ }^{66}$ Elevated IOP and reduced VA were reported as less likely to occur in the ReSure group when compared with a control group. ${ }^{67}$ The sealant was also significantly better than sutures at averting fluid egress in the first 7 days after cataract surgery. ${ }^{8}$ Singleplane incisions receiving the ReSure Sealant leaked $4.1 \%$ of the time, whereas those receiving sutures leaked $34.1 \%$ of the time. ${ }^{8}$ This is likely because the ReSure Sealant is more effective at capturing leaks. ${ }^{66}$ Sutures only put point tension on the wound, so the wound can still open on either side of the suture, whereas the sealant covers the entirety of the incision.

The ReSure Sealant is able to keep wounds apposed because of its ability to maintain a smooth, elastic layer on the de-epithelialized surface and only sloughs off in tears once the tissue has fully regenerated. ${ }^{8,66,67}$ The sealant is soft and lubricious which precludes the need for a bandage contact lens. The ReSure Sealant exhibited good healing, safety, and comfort. ${ }^{8,66,67}$ Unlike fibrin adhesives, the sealant does not carry a risk of viral transmission due to its synthetic nature. Unlike sutures, the sealant demonstrated lower device-related complications and less need for premature removal. ${ }^{8}$ If necessary, premature removal of the hydrogel sealant, without damaging the corneal bed, is possible with forceps. ${ }^{8}$

\section{Discussion}

CCIs often are not watertight at the conclusion of cataract surgery and this has been reported to increase the risk of anterior chamber fluid egress..$^{2-4,8}$ Current methods used to minimize wound leaks do not provide definitive wound closure and may result in other risks. ${ }^{5,21,22,25,29,31}$ Current wound closure standards seem inadequate. The effectiveness of stromal hydration has been questioned and its duration may vary depending on the patient's corneal endothelial function. ${ }^{1,19,37}$ Sutures may not always prevent leaks and have been associated with complications including astigmatism and increased infection risk. . $^{8,14,19,44} 49,52$
The development of wound closure products is driven by the concerns raised by the current standards of care; of these products, the PEG group has shown the most promise. The ReSure Sealant is an FDA-approved PEG hydrogel product with studies showing its safety and efficacy in preventing leaks after cataract surgery, ${ }^{8,66,67}$ with a study demonstrating its ability to prevent leaks significantly better than sutures. ${ }^{8}$ Compared to stromal hydration, the ReSure Sealant sloughs off when the tissue reepithelializes as opposed to stromal hydration, which may be dependent on the patient's endothelial pumping mechanism. ${ }^{37}$ Compared to sutures, the ReSure Sealant's smooth surface and its natural ability to slough off once the tissue re-epithelializes decreases device-related adverse events. ${ }^{8,66}$

An appropriate sealant would be helpful for a large number of patients including those having complex cataract surgeries, and those with an increased risk of potential complications from wound leaks. ${ }^{66}$ Complex cataract cases include patients with floppy iris syndrome, since additional wound manipulation may cause the incision to stretch or gape during surgery. Cataract patients with previous glaucoma-filtering surgery may also benefit from a watertight incision to minimize IOP fluctuations or hypotony. Furthermore, post-radial keratotomy, LASIK, and photorefractive keratectomy patients are more vulnerable to complications and would benefit from more definitive wound closure. In general, previous ocular surgeries or combined ocular surgeries put patients at higher risk for incision leaks and would benefit from sealant use. Monocular patients, patients with diabetes, and immunocompromised individuals, such as those undergoing chemotherapy or receiving long-term systemic steroids, would also benefit from definitive wound closure. Wound leaks should also be minimized in those affected by methicillin-resistant $S$. aureus and autoimmune disorders. In addition, obese patients appear to experience more IOP fluctuations and are at an increased risk for wound leaks. Patients with mental disabilities, dementia, and Alzheimer's may not be able to follow PO instructions, such as avoiding eye rubbing, and would benefit from sealant application.

It will also be beneficial to use a sealant in patients who desire the best refractive results. An incision that is not adequately sealed may increase the risk of IOL decentration, potentially affecting the clinical outcome. ${ }^{14} \mathrm{~A}$ study on human cadaver eyes demonstrated that a toric IOL can rotate anywhere from 5.8 to 41 degrees depending on the extent of the wound leak; this amount of rotation can decrease the effectiveness of the toric IOL and negatively impact visual outcomes. ${ }^{11}$ Those patients electing an advanced technology IOL such as a toric lens or an accommodative presbyopia-correcting lens may be good candidates for sealant use to better 
ensure the stability of the lens position. ${ }^{66}$ Avoiding sutures and stromal hydration in patients paying a premium for these IOLs would appear prudent to minimize the potential adverse events associated with sutures ${ }^{8}$ and stromal hydration. ${ }^{37}$

\section{Conclusion}

Definitive wound closure is critical to the overall success of cataract surgery. Current standards of care, such as stromal hydration and sutures, do not appear to provide sufficient wound integrity to guarantee a definitive seal. They have also been associated with unwanted adverse events. The new FDAapproved PEG hydrogel sealant may offer ophthalmic surgeons a better means of wound closure by improving wound integrity and reducing the potential for adverse events.

\section{Acknowledgment}

Preparation of this manuscript was supported with funding to Science in Vision from Ocular Therapeutix, Bedford, MA, USA.

\section{Disclosure}

Dr Matossian is a consultant to Ocular Therapeutix. No author has any proprietary or financial interest in the products or methods discussed. The authors report no conflicts of interest in this work.

\section{References}

1. Calladine D, Packard R. Clear corneal incision architecture in the immediate postoperative period evaluated using optical coherence tomography. J Cataract Refract Surg. 2007;33(8):1429-1435.

2. Chee SP. Clear corneal incision leakage after phacoemulsificationdetection using povidone iodine 5\%. Int Ophthalmol. 2005;26(4-5): 175-179.

3. Stratas BA. Clear corneal paracentesis: a case of chronic wound leakage in a patient having bimanual phacoemulsification. $J$ Cataract Refract Surg. 2005;31(5):1075.

4. Slettedal JK, Bragadóttir R. Total iris expulsion through a sutureless cataract incision due to vomiting. Acta Ophthalmol Scand. 2005; 83(1):111-112.

5. Kashiwabuchi FK, Khan YA, Rodrigues MW Jr, Wang J, McDonnell PJ, Daoud YJ. Seidel and India ink tests assessment of different clear cornea side-port incision configurations. Graefes Arch Clin Exp Ophthalmol. 2013;251(8):1961-1965.

6. Coleman DJ, Trokel S. Direct-recorded intraocular pressure variations in a human subject. Arch Ophthalmol. 1969;82(5):637-640.

7. McDonnell PJ, Taban M, Sarayba M, et al. Dynamic morphology of clear corneal cataract incisions. Ophthalmology. 2003;110(12):2342-2348.

8. Masket S, Hovanesian JA, Levenson J, et al. Hydrogel sealant versus sutures to prevent fluid egress after cataract surgery. J Cataract Refract Surg. 2014;40(12):2057-2066.

9. Dubey R, Brettell DJ, Montfort J, Coroneo MT, Francis IC. Obviating endophthalmitis after cataract surgery: excellent wound closure is the key. Arch Ophthalmol. 2011;129(11):1504-1505.

10. Wallin T, Parker J, Jin Y, Kefalopoulos G, Olson RJ. Cohort study of 27 cases of endophthalmitis at a single institution. $J$ Cataract Refract Surg. 2005;31(4):735-741.
11. Pereira FA, Milverton EJ, Coroneo MT. Miyake-Apple study of the rotational stability of the Acrysof Toric intraocular lens after experimental eye trauma. Eye (Lond). 2010;24(2):376-378.

12. Hayashi K, Tsuru T, Yoshida M, Hirata A. Intraocular pressure and wound status in eyes immediately after scleral tunnel incision and clear corneal incision cataract surgery. Am J Ophthalmol. 2014;158(2):232-241.

13. Thoms SS, Musch DC, Soong HK. Postoperative endophthalmitis associated with sutured versus unsutured clear corneal cataract incisions. Br J Ophthalmol. 2007;91(6):728-730.

14. Uy HS, Kenyon KR. Surgical outcomes after application of a liquid adhesive ocular bandage to clear corneal incisions during cataract surgery. J Cataract Refract Surg. 2013;39(11):1668-1674.

15. Chung CF, Lai JS. Inflow of ocular surface fluid through clear corneal cataract incisions: a laboratory model. Am J Ophthalmol. 2005; 139(3):576

16. Wong RW, Kokame GT, Mahmoud TH, Mieler WF, Tornambe PE, McDonald HR. Complications associated with clear corneal cataract wounds during vitrectomy. Retina. 2010;30(6):850-855.

17. Cheng CJ, Stark WJ. Wound instability and management after cataract surgery in a patient with prior laser in situ keratomileusis. $J$ Cataract Refract Surg. 2007;33(7):1315-1317.

18. May WN, Castro-Combs J, Quinto GG, Kashiwabuchi R, Gower EW, Behrens A. Standardized Seidel test to evaluate different sutureless cataract incision configurations. J Cataract Refract Surg. 2010; 36(6):1011-1017.

19. Masket S, Hovanesian J, Raizman M, Wee D, Fram N. Use of a calibrated force gauge in clear corneal cataract surgery to quantify point-pressure manipulation. J Cataract Refract Surg. 2013;39(4):511-518.

20. Faulkner HW. Association between clear corneal cataract incisions and postoperative endophthalmitis. J Cataract Refract Surg. 2007;33(4):562.

21. Vasavada V, Vasavada AR, Vasavada VA, Srivastava S, Gajjar DU, Mehta S. Incision integrity and postoperative outcomes after microcoaxial phacoemulsification performed using 2 incision-dependent systems. J Cataract Refract Surg. 2013;39(4):563-571.

22. Waheeb S. Topical anesthesia in phacoemulsification. Oman J Ophthalmol. 2010;3(3):136-139.

23. Lundström M, Wejde G, Stenevi U, Thorburn W, Montan P. Endophthalmitis after cataract surgery: a nationwide prospective study evaluating incidence in relation to incision type and location. Ophthalmology. 2007;114(5):866-870.

24. Beselga D, Campos A, Castro M, et al. Postcataract surgery endophthalmitis after introduction of the ESCRS protocol: a 5-year study. Eur $J$ Ophthalmol. 2014;24(4):516-519.

25. Lloyd JC, Braga-Mele R. Incidence of postoperative endophthalmitis in a high-volume cataract surgicentre in Canada. Can J Ophthalmol. 2009;44(3):288-292.

26. May W, Castro-Combs J, Camacho W, Wittmann P, Behrens A. Analysis of clear corneal incision integrity in an ex vivo model. $J$ Cataract Refract Surg. 2008;34(6):1013-1018.

27. Masket S, Belani S. Proper wound construction to prevent short-term ocular hypotony after clear corneal incision cataract surgery. J Cataract Refract Surg. 2007;33(3):383-386.

28. Sykakis E, Karim R, Kinsella M, Bhogal M, Patel S, Parmar DN. Study of fluid ingress through clear corneal incisions following phacoemulsification with or without the use of a hydrogel ocular bandage: a prospective comparative randomised study. Acta Ophthalmol. Epub 2014 May 4.

29. Johnson CS, Wathier M, Grinstaff M, Kim T. In vitro sealing of clear corneal cataract incisions with a novel biodendrimer adhesive. Arch Ophthalmol. 2009;127(4):430-434.

30. Teuma EV, Bott S, Edelhauser HF. Sealability of ultrashort-pulse laser and manually generated full-thickness clear corneal incisions. J Cataract Refract Surg. 2014;40(3):460-468.

31. Grewal DS, Basti S. Intraoperative vertical gas breakthrough during clear corneal incision creation with the femtosecond cataract laser. J Cataract Refract Surg. 2014;40(4):666-670. 
32. Mastropasqua L, Toto L, Mastropasqua A, et al. Femtosecond laser versus manual clear corneal incision in cataract surgery. J Refract Surg. 2014;30(1):27-33.

33. Lee H, Kim EK, Kim HS, Kim TI. Fourier-domain optical coherence tomography evaluation of clear corneal incision structure according to blade material. J Cataract Refract Surg. 2014;40(10):1615-1624.

34. Can I, Bayhan HA, Celik H, Bostancı Ceran B. Anterior segment optical coherence tomography evaluation and comparison of main clear corneal incisions in microcoaxial and biaxial cataract surgery. J Cataract Refract Surg. 2011;37(3):490-500.

35. Francis IC, Roufas A, Figueira EC, Pandya VB, Bhardwaj G, Chui J. Endophthalmitis following cataract surgery: the sucking corneal wound. J Cataract Refract Surg. 2009;35(9):1643-1645.

36. Vasavada AR, Praveen MR, Pandita D, et al. Effect of stromal hydration of clear corneal incisions: quantifying ingress of trypan blue into the anterior chamber after phacoemulsification. J Cataract Refract Surg. 2007;33(4):623-627.

37. Walters TR. The effect of stromal hydration on surgical outcomes for cataract patients who received a hydrogel ocular bandage. Clin Ophthalmol. 2011;5:385-391.

38. Fine IH, Hoffman RS, Packer M. Profile of clear corneal cataract incisions demonstrated by ocular coherence tomography. J Cataract Refract Surg. 2007;33(1):94-97.

39. Fukuda S, Kawana K, Yasuno Y, Oshika T. Wound architecture of clear corneal incision with or without stromal hydration observed with 3-dimensional optical coherence tomography. Am J Ophthalmol. 2011; 151(3):413-419.

40. Mifflin MD, Kinard K, Neuffer MC. Comparison of stromal hydration techniques for clear corneal cataract incisions: conventional hydration versus anterior stromal pocket hydration. J Cataract Refract Surg. 2012;38(6):933-937.

41. Calladine D, Tanner V. Optical coherence tomography of the effects of stromal hydration on clear corneal incision architecture. J Cataract Refract Surg. 2009;35(8):1367-1371.

42. Hu YJ, Hou P, Chen WQ. Factors affecting stromal hydration of clear corneal incision architecture. J Cataract Refract Surg. 2010;36(3): 528.

43. Alió JL, Mulet ME, Cotlear D, Molina Y, Kremer I, Martin JM. Evaluation of a new bioadhesive copolymer (ADAL) to seal corneal incisions. Cornea. 2004;23(2):180-189.

44. May WN, Castro-Combs J, Kashiwabuchi RT, et al. Bacterial-sized particle inflow through sutured clear corneal incisions in a laboratory human model. J Cataract Refract Surg. 2011;37(6):1140-1146.

45. Nichamin LD, Chang DF, Johnson SH, et al. American Society of Cataract and Refractive Surgery Cataract Clinical Committee. ASCRS White Paper: what is the association between clear corneal cataract incisions and postoperative endophthalmitis? J Cataract Refract Surg. 2006;32(9):1556-1559.

46. Bar-Sela SM, Spierer O, Spierer A. Suture-related complications after congenital cataract surgery: Vicryl versus Mersilene sutures. J Cataract Refract Surg. 2007;33(2):301-304.

47. Hillier RJ, Ajit RR, Kelly SP. Suture-related complications after cataract surgery: a patient safety issue. J Cataract Refract Surg. 2009; 35(11):2035.

48. Lee BJ, Smith SD, Jeng BH. Suture-related corneal infections after clear corneal cataract surgery. J Cataract Refract Surg. 2009;35(5): 939-942.

49. Heaven CJ, Davison CR, Cockcroft PM. Bacterial contamination of nylon corneal sutures. Eye (Lond). 1995;9(Pt 1):116-118.

50. Noguera G, Lee WS, Castro-Combs J, et al. Novel laser-activated solder for sealing corneal wounds. Invest Ophthalmol Vis Sci. 2007;48(3): 1038-1042.
51. Shahbazi J, Marçal H, Watson S, Wakefield D, Sarris M, Foster LJ. Sutureless sealing of penetrating corneal wounds using a laser-activated thin film adhesive. Lasers Surg Med. 2011;43(6):490-498.

52. May WN, Castro-Combs J, Kashiwabuchi RT, et al. Sutured clear corneal incision: wound apposition and permeability to bacterial-sized particles. Cornea. 2013;32(3):319-325.

53. Tan CS. Suture-related corneal infections: should all sutures be routinely removed after phacoemulsification? J Cataract Refract Surg. 2009;35(12):2179-2180.

54. Ku JJ, Wei MC, Amjadi S, Montfort JM, Singh R, Francis IC. Role of adequate wound closure in preventing acute postoperative bacterial endophthalmitis. J Cataract Refract Surg. 2012;38(7):1301-1302.

55. Strehin I, Ambrose WM, Schein O, Salahuddin A, Elisseeff J. Synthesis and characterization of a chondroitin sulfate-polyethylene glycol corneal adhesive. J Cataract Refract Surg. 2009;35(3):567-576.

56. Bhatia SS. Ocular surface sealants and adhesives. Ocul Surf. 2006; 4(3):146-154.

57. Meskin SW, Ritterband DC, Shapiro DE, et al. Liquid bandage (2-octyl cyanoacrylate) as a temporary wound barrier in clear corneal cataract surgery. Ophthalmology. 2005;112(11):2015-2021.

58. Banitt M, Malta JB, Soong HK, Musch DC, Mian SI. Wound integrity of clear corneal incisions closed with fibrin and N-butyl-2-cyanoacrylate adhesives. Curr Eye Res. 2009;34(8):706-710.

59. Chen WL, Lin CT, Hsieh CY, Tu IH, Chen WY, Hu FR. Comparison of the bacteriostatic effects, corneal cytotoxicity, and the ability to seal corneal incisions among three different tissue adhesives. Cornea. 2007;26(10):1228-1234.

60. Proaño CE, Mulroy L, Jones E, Azar DT, Redmond RW, Kochevar IE. Photochemical keratodesmos for bonding corneal incisions. Invest Ophthalmol Vis Sci. 2004;45(7):2177-2181.

61. Hovanesian JA, Karageozian VH. Watertight cataract incision closure using fibrin tissue adhesive. J Cataract Refract Surg. 2007; 33(8):1461-1463.

62. Kim T, Kharod BV. Tissue adhesives in corneal cataract incisions. Curr Opin Ophthalmol. 2007;18(1):39-43.

63. Menabuoni L, Pini R, Rossi F, Lenzetti I, Yoo SH, Parel JM. Laserassisted corneal welding in cataract surgery: retrospective study. J Cataract Refract Surg. 2007;33(9):1608-1612.

64. Rasier R, Ozeren M, Artunay O, et al. Corneal tissue welding with infrared laser irradiation after clear corneal incision. Cornea. 2010; 29(9):985-990.

65. Maddula S, Davis DK, Ness PJ, Burrow MK, Olson RJ. Comparison of wound strength with and without a hydrogel liquid ocular bandage in human cadaver eyes. J Cataract Refract Surg. 2010; 36(10):1775-1778.

66. Calladine D, Ward M, Packard R. Adherent ocular bandage for clear corneal incisions used in cataract surgery. J Cataract Refract Surg. 2010;36(11):1839-1848.

67. Dell SJ, Hovanesian JA, Raizman MB, et al. Ocular Bandage Study Group. Randomized comparison of postoperative use of hydrogel ocular bandage and collagen corneal shield for wound protection and patient tolerability after cataract surgery. J Cataract Refract Surg. 2011; 37(1):113-121.

68. www.fda.gov [homepage on the Internet]. Ocular Therapeutix: Ophthalmic devices panel executive summary - ReSure ${ }^{\circledR}$ Sealant; September 19, 2013 [meeting date; cited 2015 Feb 15]. Available from: http:// www.fda.gov/downloads/AdvisoryCommittees/CommitteesMeetingMaterials/MedicalDevices/MedicalDevicesAdvisoryCommittee/ OphthalmicDevicesPanel/UCM368596.pdf. Accessed February 15, 2015. 


\section{Publish your work in this journal}

Clinical Ophthalmology is an international, peer-reviewed journal covering all subspecialties within ophthalmology. Key topics include: Optometry; Visual science; Pharmacology and drug therapy in eye diseases; Basic Sciences; Primary and Secondary eye care; Patient Safety and Quality of Care Improvements. This journal is indexed on

Submit your manuscript here: http://www.dovepress.com/clinical-ophthalmology-journal
PubMed Central and CAS, and is the official journal of The Society of Clinical Ophthalmology (SCO). The manuscript management system is completely online and includes a very quick and fair peer-review system, which is all easy to use. Visit http://www.dovepress.com/ testimonials.php to read real quotes from published authors. 